\title{
NOVOS POEMAS DOS NOVOS POEMAS DE RILKE
}

\section{Guilherme Gontijo Flores e Mauricio Mendonça Cardozo}

\begin{abstract}
...quanto a meus livros, gostaria de mandar-lhe todos os que lhe pudessem agradar. Mas sou muito pobre e meus livros, mal publicados, não me pertencem mais. Eu mesmo não os posso comprar, nem dar, portanto - como tão frequentemente teria vontade de fazê-lo -, a quem lhes demonstra afeição.

Eis porque me restrinjo a escrever-lhe num papel os títulos de meus livros mais recentes. Deixo a seu cuidado encomendar algum deles.
\end{abstract}

R. M. Rilke, Cartas a um jovem poeta

Há muito que a obra do poeta Rainer Maria Rilke encontra ressonância entre nós, leitores brasileiros. Aliás, ao contrário de vários autores importantes, que foram traduzidos apenas muito episodicamente, Rilke figura entre os poucos autores de língua alemã que, tanto no Brasil quanto em Portugal, contam com uma recepção contínua já desde a década de 20 do século passado, seja pela edição de novas traduções, seja pela reedição de traduções já existentes. São responsáveis pela construção desse cenário tão produtivo da recepção de Rilke no Brasil ${ }^{1}$, nomes como Cecília Meireles, Dora Ferreira da Silva, Paulo Rónai, Geir Campos, Emmanuel Carneiro Leão, Karlos Rischbieter, José Paulo Paes, Augusto de Campos, Janice Caiafa, Bruno Silva D’Abruzzo, Guilherme Gontijo Flores, Tercio Redondo, entre outros de uma lista muito mais extensa, que não cessa de crescer e é representativa do estatuto de uma obra que, a cada geração, é descoberta em suas novas faces de atualidade.

E, como é de se esperar de um poeta lido e relido por tantas gerações diferentes, a cada nova época parece configurar-se um novo Rilke no horizonte de recepção: por vezes aprofundando e reafirmando um padrão anterior de leitura, por vezes tensionando um viés crítico já estabelecido e desafiando a crítica ao enfrentamento de uma visão mais complexa de sua obra. Coube ao jogo da crítica, em seus diversos momentos e na figura de seus tantos agentes, tanto refutar essas novas tendências, contentando-se com a disputa por determinada forma de ver o poeta, quanto dispor-se a pensar um Rilke que, a um só tempo, concentra suas

\footnotetext{
${ }^{1}$ Em virtude da dificuldade de acesso à bibliografia específica, este trabalho não pôde levar em conta as traduções de Rilke publicadas em Portugal. No entanto, não podemos deixar de mencionar o nome de Paulo Quintela, um dos pioneiros e mais importantes tradutores de literatura de língua alemã em Portugal e que também traduziu Rilke.
} 
faces de poeta do ser (como o que teria tido impacto sobre a obra de Heidegger), de poeta dos poemas-coisa (movido pelas lições de Rodin), de poeta de uma poesia pensante (como em seus sonetos e elegias), e de tantos mais poetas que nele habitam, já descobertos ou ainda por descobrir.

É no entanto necessário lembrar que, a despeito de sua tradução extensiva ao longo de já quase um século, grande parte de sua obra ainda mantém-se inédita em língua portuguesa. Se, por um lado, livros de poemas como as Elegias de Duíno, os Sonetos a Orfeu e o Livro de Horas foram já integralmente traduzidos para nosso idioma - mérito da geração de 40 e 50, que reconheceria nesses livros o momento máximo da obra do poeta - , por outro lado, obras igualmente relevantes, como O livro de Imagens e os Novos Poemas, para não mencionar aqui toda a obra de Rilke em língua francesa, foram traduzidas apenas parcialmente, em um semnúmero de antologias e publicações isoladas em revistas.

A forma da antologia é absolutamente legítima e, sabidamente, cumpre muito bem a função de apresentação de parte da obra de um poeta num novo contexto, estrangeiro ou não. E é também objeto de grande interesse crítico, na medida em que se pode flagrar, no próprio gesto de seleção e reorganização dos poemas que passam a integrar a antologia, um recorte representativo de determinada visão crítica do organizador-tradutor. No entanto, sem menosprezar o mérito de todo esforço tradutório que, mesmo mais pontualmente, tenha tido em vista trazer para nosso cenário de recepção algo da obra desse grande poeta, é mais do que chegada a hora de nos perguntarmos se não seria o momento de pensar também em projetos de tradução de Rilke que não se restringissem apenas a recortes de sua obra, mas oferecessem, ao leitor brasileiro, cada um de seus livros de poemas na condição de unidade poemática que constitui sua obra completa.

Partindo dessa perspectiva, apresentamos, a seguir, alguns poemas que resultam de nosso projeto de tradução, in statu nascendi, do conjunto de poemas que integra as duas partes da obra intitulada Novos Poemas: Neue Gedichte, de 1907, e Der neuen Gedichte anderer Teil, de 1908. De acordo com o levantamento preliminar que realizamos ${ }^{2}$, de um total de 174 poemas $^{3}$, menos de um terço (54) desses poemas foram publicados em tradução no Brasil na forma de livro: 30 oriundos dos 73 que integram as Neue Gedichte e 24 advindos dos 101 que formam o Der neuen Gedichte anderer Teil, sendo que muitos desses 54 poemas

\footnotetext{
${ }^{2}$ Levantamento não exaustivo, realizado com base nas seguintes obras: RILKE, R. M. Senhor, é tempo: poemas selecionados, tradução de Karlos Rischbieter. Curitiba: Posigraf, 1993. RILKE, R. M. Poemas - Rainer Maria Rilke, tradução de José Paulo Paes. São Paulo: Companhia das Letras, 1993. RILKE, R. M. Rilke: poesia-coisa, tradução de Augusto de Campos. Rio de Janeiro: Imago, 1994. RILKE, R. M. Coisas e anjos de Rilke, tradução de Augusto de Campos. São Paulo: Perspectiva, 2001.

${ }^{3}$ Conforme cotejo das edições críticas aqui utilizadas: RILKE, 2001 e 1996.
} 
já traduzidos foram contemplados com mais de uma tradução. Mas são 120 os poemas dessa obra que ainda mantêm-se inéditos em tradução brasileira, o que, por um lado, causa espanto no caso de obra tão central de um poeta tão importante como Rilke, ao mesmo tempo em que, por outro lado, dá a real dimensão do impacto que a prática corrente de publicação de poesia estrangeira no Brasil, quase que exclusivamente na forma de antologias, é capaz de produzir sobre a recepção da obra de determinado poeta, reduzindo-a a fragmentos.

Dadas as limitações de espaço no âmbito de um trabalho como este, selecionamos 20 poemas, privilegiando a apresentação de textos que, até onde temos notícia, ainda não haviam sido publicados na forma de livro no Brasil. Procuramos privilegiar também, em nossa seleção, poemas que se articulam em torno de alguns eixos temáticos produtivos na obra do poeta, como o da feminilidade, do amor, da religiosidade, da loucura e da passagem da infância. A ordem dos poemas segue a sequência de publicação na obra em alemão. As traduções são identificadas com o nome de seus tradutores, mas resultam de um diálogo intenso e de um trabalho bastante profícuo a quatro mãos. Como texto de referência para esta tradução, valemo-nos da edição cronológica publicada pela Editora Insel (Rilke, 2011), que remonta à edição de Ernst Zinn das obras completas de Rilke, cotejada com a edição crítica comentada, em 4 volumes, publicada pela mesma editora (Rilke, 1996).

A epígrafe que abre este trabalho e retoma a parte final das Cartas a um jovem poeta, citada aqui na tradução de Paulo Rónai, dá notícia da condição financeira limitada desse poeta que passou boa parte de sua vida às custas do apoio de mecenas. Mas, de suas entrelinhas, ergue-se também uma questão que diz respeito à noção de propriedade da obra. Questão que não se apresenta como menor no contexto de um projeto de tradução de uma obra que, diznos o poeta, não se pode comprar, tampouco dar, nem mesmo quando na condição de autor. Trata-se, portanto, da tradução da obra de um autor que, tomando suas palavras nesse outro sentido, parece advertir-nos dos limites de presumirmos, como certa, tal possibilidade de apropriação no exercício de leitura e tradução que se nos impõem no horizonte dessa tarefa. Enfim, trata-se da tradução desse autor que, sem poder presentear-nos com sua obra, deixa-a “a nosso cuidado". Cabe portanto a nós, tradutores, lembrarmos que é na condição de alguém que faz escolhas diante dos limites sempre incertos daquilo que, no outro, é próprio - e não no horizonte ilusório de uma certeza de sua propriedade - , que se constrói esse cuidado com a obra do outro, com a obra de um outro, que, aqui, deixamos agora aos cuidados de nossos leitores. 


\section{Früher Apollo}

Wie manches Mal durch das noch unbelaubte Gezweig ein Morgen durchsieht, der schon ganz im Frühling ist: so ist in seinem Haupte nichts was verhindern könnte, daß der Glanz.

aller Gedichte uns fast tödlich träfe; denn noch kein Schatten ist in seinem Schaun, $z u$ kühl für Lorbeer sind noch seine Schläfe und später erst wird aus den Augenbraun

hochstämmig sich der Rosengarten heben, aus welchem Blätter, einzeln, ausgelöst hintreiben werden auf des Mundes Beben,

der jetzt noch still ist, niegebraucht und blinkend und nur mit seinem Lächeln etwas trinkend als würde ihm sein Singen eingeflößt.

\section{Apolo primitivo}

Como por vezes dentre desfolhada rama se vê a aurora, inteira em pura primavera; em sua cabeça nada é capaz de impedir que o que fulgura

na poesia nos fira um golpe cruel; pois não existem sombras no seu rosto, as têmporas são frias pr' o laurel, e mais tarde dos cílios, de alto posto,

excelso roseiral surge da toca, e cada pétala caída, quanto ganha vida no tremular da boca

sempre imóvel, sem uso, reluzente, e em seu sorriso algo de absorvente sorve, como se lhe insuflassem canto. 


\section{Mädchen-Klage}

Diese Neigung, in den Jahren, da wir alle Kinder waren, viel allein zu sein, war mild; andern ging die Zeit im Streite, und man hatte seine Seite, seine Nähe, seine Weite, einen Weg, ein Tier, ein Bild.

Und ich dachte noch, das Leben hörte niemals auf zu geben, daß man sich in sich besinnt. Bin ich in mir nicht im Größten? Will mich Meines nicht mehr trösten und verstehen wie als Kind?

Plötzlich bin ich wie verstoßen, und zu einem Übergroßen wird mir diese Einsamkeit, wenn, auf meiner Brüste Hügeln stehend, mein Gefühl nach Flügeln oder einem Ende schreit.

\section{Lamento de menina}

Esse jeito de estarmos nós quando crianças sempre a sós, era-nos leve em sua ventura; outros viviam o tempo instante e cada qual em seu quadrante, em seu mais rente, mais distante, um onde, um bicho, uma figura.

E eu ainda achava que a vida provava em suas vindas e idas, que a gente é a gente e não se cansa. Não serei em mim algo maior? O que de mim não sei de cor, nem mais me entende como criança?

Então, como se me apartasse, e por demais se agigantasse a solidão imensa em mim, grita, dos morros de meus seios, um sentimento todo anseio ou por asas, ou por um fim. 


\section{Eranna an Sappho}

O du wilde weite Werferin:

Wie ein Speer bei andern Dingen

lag ich bei den Meinen. Dein Erklingen

warf mich weit. Ich weiß nicht wo ich bin.

Mich kann keiner wiederbringen.

Meine Schwestern denken mich und weben, und das Haus ist voll vertrauter Schritte.

Ich allein bin fern und fortgegeben,

und ich zittere wie eine Bitte;

denn die schöne Göttin in der Mitte

ihrer Mythen glüht und lebt mein Leben.

\section{Erina a Safo}

Você, livre, lívida lanceira:

entre os meus, qual dardo eu fui pousar junto aos outros. Mas o teu pulsar me lançou longe. Sem eira, ou beira, ninguém pode me buscar.

Pensam-me as irmãs e tecem telas, casa cheia, vozes conhecidas. $\mathrm{Eu}$, somente, tão distante delas, feito prece, eis-me estremecida; pois, em meio aos mitos, uma bela deusa arde e vive a minha vida. 


\section{Sappho an Eranna}

Unruh will ich über dich bringen, schwingen will ich dich, umrankter Stab. Wie das Sterben will ich dich durchdringen und dich weitergeben wie das Grab an das Alles: allen diesen Dingen.

\section{Safo a Erina}

Tirso de hera, quero balançar-te; à inquietude quero conduzir-te.

Quero, como a morte, atravessar-te; como a sepultura transmitir-te para o Todo: a tudo em toda parte.

Tradução de Guilherme Gontijo Flores 


\section{Sappho an Alkaïos}

Fragment

Und was hättest du mir denn zu sagen, und was gehst du meine Seele an, wenn sich deine Augen niederschlagen vor dem nahen Nichtgesagten? Mann,

sieh, uns hat das Sagen dieser Dinge hingerissen und bis in den Ruhm. Wenn ich denke: unter euch verginge dürftig unser süßes Mädchentum,

welches wir, ich Wissende und jene mit mir Wissenden, vom Gott bewacht, trugen unberührt, daß Mytilene wie ein Apfelgarten in der Nacht duftete vom Wachsen unsrer Brüste -

$J a$, auch dieser Brüste, die du nicht wähltest wie zu Fruchtgewinden, Freier mit dem weggesenkten Angesicht. Geh und laß mich, daß zu meiner Leier komme, was du abhältst: alles steht.

Dieser Gott ist nicht der Beistand Zweier, aber wenn er durch den Einen geht

\section{Safo a Alceu \\ Fragmento}

O que você viria me contar, com minha alma o que teria a ver, se os teus olhos vêm se rebaixar ante o quase não-dito ? O dizer

dessas coisas, saiba, nos detém e nos arrasta até o resplendor. Quando eu penso: vocês já além do viço doce, de seu frescor,

que nós, eu sábia e mais alguma também sábia, enquanto Deus esgueira, guardamos: Mitilene perfuma, noturna, um jardim de macieira que exala o crescer dos nossos seios -

Sim, destes seios, que você não acolhe em suas coroas de fruta, noivo de olhos baixos pelo chão. Vá, me deixe; e o que em você reluta venha à minha lira: tudo cala.

Este Deus a dois não presta escuta, mas se acaso apenas um abala 


\section{Grabmal eines jungen Mädchens}

Wir gedenkens noch. Das ist, als müßte alles dieses einmal wieder sein.

Wie ein Baum an der Limonenküste trugst du deine kleinen leichten Brüste in das Rauschen seines Bluts hinein:

— jenes Gottes. Und es war der schlanke Flüchtling, der Verwöhnende der Fraun. Sïß und glühend, warm wie dein Gedanke, überschattend deine frühe Flanke und geneigt wie deine Augenbraun.

\section{Lápide de uma menina moça}

Rememoramos ainda. Ei-lo, todo o então, como se fosse agora. Como da Riviera o limoeiro, você deitou mimos de teus seios no sangue daquele que rumora:

— daquele Deus.

E foi o arredio bibelô de jovens e mais velhas. Doce e ardente, era da ideia o cio, era a sombra sobre teu quadril e o arco de tuas sobrancelhas. 


\section{Opfer}

$O$ wie blüht mein Leib aus jeder Ader duftender, seitdem ich dich erkenn; sieh, ich gehe schlanker und gerader, und du wartest nur -: wer bist du denn?

Sieh: ich fühle, wie ich mich entferne, wie ich Altes, Blatt um Blatt, verlier. Nur dein Lächeln steht wie lauter Sterne über dir und bald auch über mir.

Alles was durch meine Kinderjahre namenlos noch und wie Wasser glänzt, will ich nach dir nennen am Altare, der entzündet ist von deinem Haare und mit deinen Brüsten leicht bekränzt.

\section{Oferenda}

Minha carne que de cada veia floresce mais olorosa, desde que em ti me vi; meu passo que, mais reto, mais embevece, mas quem é você, que me vigia aqui?

Sinto que a distância em mim se desfivela, folha após folha, o tempo se apaga enfim. Só teu sorriso de mil e uma estrelas paira sobre ti e em breve sobre mim.

Tudo o que em minha infância eu via passar ainda sem nome, água clara que escoa, quero agora com teu nome nomear no altar que teus cabelos põem a incendiar e que a grinalda de teus seios coroa. 


\section{Östliches Taglied}

Ist dieses Bette nicht wie eine Küste, ein Küstenstreifen nur, darauf wir liegen? Nichts ist gewiß als deine hohen Brüste, die mein Gefühl in Schwindeln überstiegen.

Denn diese Nacht, in der so vieles schrie, in der sich Tiere rufen und zerreißen, ist sie uns nicht entsetzlich fremd? Und wie: was draußen langsam anhebt, Tag geheißen, ist das uns denn verständlicher als sie?

Man müßte so sich ineinanderlegen wie Blütenblätter um die Staubgefäße: so sehr ist überall das Ungemäße und häuft sich an und stürzt sich uns entgegen.

Doch während wir uns aneinander drücken, um nicht zu sehen, wie es ringsum naht, kann es aus dir, kann es aus mir sich zücken: denn unsre Seelen leben von Verrat.

\begin{abstract}
Alba do nascente
Esta cama não é como uma encosta, uma franja de encosta, em que deitamos? Os cimos dos teus seios são resposta na vertigem dos sentidos que alçamos.

Nesta noite, em que tanta coisa grita, em que a fauna esbraveja e se esfacela, não nos espanta a falta de guarida? E a hora, que de dia se faz bela, estranha menos que a noite vivida?

Deitemos um bem dentro d'outro e só, como pétalas em torno do estame: demais em toda parte é o sem liame que acede e assoma e rompe sobre nós.

Mas mesmo juntos um do outro assim, sem ver o mundo, que a nos engolir, pode partir de ti, partir de mim: pois nossas almas vivem de trair.
\end{abstract}




\section{Abisag}

Sie lag. Und ihre Kinderarme waren von Dienern um den Welkenden gebunden, auf dem lag die süßen langen Stunden, ein wenig bang vor seinen vielen Jahren.

Und manchmal wandte sie in seinem Barte ihr Angesicht, wenn eine Eule schrie; und alles, was die Nacht war, kam und scharte mit Bangen und Verlangen sich um sie.

Die Sterne zitterten wie ihresgleichen, ein Duft ging suchend durch das Schlafgemach, der Vorhang rührte sich und gab ein Zeichen, und leise ging ihr Blick dem Zeichen nach-.

Aber sie hielt sich an dem dunkeln Alten und, von der Nacht der Nächte nicht erreicht, lag sie auf seinem fürstlichen Erkalten jungfräulich und wie eine Seele leicht.

\section{II}

Der König saß und sann den leeren Tag getaner Taten, ungefühlter Lüste und seiner Lieblingshündin, der er pflag -. Aber am Abend wölbte Abisag sich über ihm. Sein wirres Leben lag verlassen wie verrufne Meeresküste unter dem Sternbild ihrer stillen Brüste.

Und manchmal, als ein Kundiger der Frauen erkannte er durch seine Augenbrauen den unbewegten, küsselosen Mund; und sah: ihres Gefühles grüne Rute neigte sich nicht herab zu seinem Grund. Ihn fröstelte. Er horchte wie ein Hund und suchte sich in seinem letzten Blute.

\section{Abisag \\ I}

Deitou-se. Um servo uniu seu pueril bracinho junto ao velho, sem demora; deitou-se ali por longa e doce hora, receosa do seu olhar senil.

Vez por outra em sua barba ela escondia o rosto, se a coruja chirriava; e tudo que era noite ali surgia e em seu pejo e desejo a encerrava.

Astros tremiam numa cena igual, um perfume corria no aposento, movia-se a cortina num sinal, sinal que o olhar seguia leve e atento.

Mas o negror da idade ela abraçava e, na noite das noites, ficou calma; deitou no régio corpo que a gelava, virginal e suave como a alma.

II

O rei lembrava no vazio do dia de seus feitos, dos gozos imperfeitos, da cadela que mais o delicia - . Mas à noite Abisag o recobria como concha. Sua vida era arredia, deserto mar infame entre meneios sob as constelações daqueles seios.

Vez por outra, versado nas mulheres, via entre as sobrancelhas desses seres a boca inda sem beijo, intacta taça; logo soube: seu fundo, não acalça aquela verde verga do sentir. Tremia. Ele, atento cão de caça, buscava-se em seu sangue a sucumbir. 


\section{Gesang der Frauen an den Dichter}

Sieh, wie sich alles auftut: so sind wir; denn wir sind nichts als solche Seligkeit. Was Blut und Dunkel war in einem Tier, das wuchs in uns zur Seele an und schreit

als Seele weiter. Und es schreit nach dir. Du freilich nimmst es nur in dein Gesicht als sei es Landschaft: sanft und ohne Gier. Und darum meinen wir, du bist es nicht, nach dem es schreit. Und doch, bist du nicht der, an den wir uns ganz ohne Rest verlören? Und werden wir in irgend einem mehr?

Mit uns geht das Unendliche vorbei. Du aber sei, du Mund, daß wir es hören, du aber, du Uns-Sagender: du sei.

\section{Canto das mulheres ao poeta}

Como tudo que surje: somos tal e qual, de uma alegria que não finda. O que era sangue e sombra no animal, cresceu em nós como alma e grita ainda

como alma. E é por ti que grita e clama. Você de certo sente e só cogita o olhar sem rosto: tépido e sem gana. Não, não achamos que é por ti que grita.

Mas não seria enfim você, quiçais, aquele um em quem nos consumimos? E nalgum outro, havemos de ainda mais?

Conosco o infinito um fim enseja. Você, boca, você seja, que ouvimos, você, o que-nos-diz: você, que seja. 


\section{Buddha}

Als ob er horchte. Stille: eine Ferne...

Wir halten ein und hören sie nicht mehr. Und er ist Stern. Und andre große Sterne, die wir nicht sehen, stehen um ihn her.

O er ist Alles. Wirklich, warten wir, daß er uns sähe? Sollte er bedürfen? Und wenn wir hier uns vor ihm niederwürfen, er bliebe tief und träge wie ein Tier.

Denn das, was uns zu seinen Füßen reißt, das kreist in ihm seit Millionen Jahren. $E r$, der vergißt was wir erfahren und der erfährt was uns verweist.

\section{Buda}

Como ouvisse. Silêncio: uma distância... Nós paramos e não ouvimos mais. E ele é astro. E outros astros abissais, que não vemos, em torno têm estância.

Oh, ele é tudo. Então o que se espera, que ele nos veja? É o que ele quer, talvez? Se nos prostrássemos perante os pés, descansaria inerte feito fera.

Pois há milhões de anos nele erra algo que faz com que aos pés nos lancemos. Ele, que esquece o que vivemos e vive no que nos esterra. 


\section{Gott im Mittelalter}

Und sie hatten Ihn in sich erspart und sie wollten, daß er sei und richte, und sie hängten schießlich wie Gewichte (zu verhindern seine Himmelfahrt)

an ihn ihrer großen Kathedralen Last und Masse. Und er sollte nur über seine grenzenlosen Zahlen zeigend kreisen und wie eine Uhr

Zeichen geben ihrem Tun und Tagwerk. Aber plötzlich kam er ganz in Gang, und die Leute der entsetzten Stadt

ließen ihn, vor seiner Stimme bang, weitergehn mit ausgehängten Schlagwerk und entflohn vor seinem Zifferblatt.

\section{Deus na Idade Média}

E eles em si mesmo $\mathrm{O}$ pouparam e queriam que, sendo, julgasse e enfim feito peso penduraram (pra não permitir que ao céu se alçasse)

em seu nome imensas catedrais: fardo e massa. Ele devia somente, sobre o seu sem-fim de numerais, marcar — qual relógio simplesmente -

o dia e a hora ao seu rigor.

Porém logo veio em pleno passo, e o povo da vila horrorizada

deixou-o, temendo a voz de aço, seguir com a máquina dependurada e escapou por fim do seu visor. 


\section{Ein Frauen-Schicksal}

So wie der König auf der Jagd ein Glas ergreift, daraus zu trinken, irgendeines, und wie hernach der welcher es besa $\beta$ es fortstellt und verwahrt als wär es keines:

so hob vielleicht das Schicksal, durstig auch, bisweilen Eine an den Mund und trank, die dann ein kleines Leben, viel zu bang sie zu zerbrechen, abseits vom Gebrauch

hinstellte in die ängstliche Vitrine, in welcher seine Kostbarkeiten sind (oder die Dinge, die für kostbar gelten).

Da stand sie fremd wie eine Fortgeliehne und wurde einfach alt und wurde blind und war nicht kostbar und war niemals selten.

\section{Um destino de mulher}

Assim como na caça o rei um copo apanha e dele bebe sem demora, e como então seu dono o mero copo guarda, como se copo nunca fora:

o destino, quiçá também com sede, aos lábios leva vez ou outra e bebe uma mulher, que não sabe se de medo, tira de uso a vida breve

e guarda-a na redoma resguardada, com as preciosidades que ele agrega (ou com as coisas ditas preciosas).

E lá, estranhamente alienada, ela fica mais velha, fica cega, não foi rara, nem nunca valorosa. 


\section{Buddha}

Schon von ferne fühlt der fremde scheue Pilger, wie es golden von ihm träuft; so als hätten Reiche voller Reue ihre Heimlichkeiten aufgehäuft.

Aber näher kommend wird er irre vor der Hoheit dieser Augenbraun: denn das sind nicht ihre Trinkgeschirre und die Ohrgehänge ihrer Fraun.

Wüßte einer denn zu sagen, welche Dinge eingeschmolzen wurden, um dieses Bild auf diesem Blumenkelche

aufzurichten: stummer, ruhiggelber als ein goldenes und rundherum auch den Raum berührend wie sich selber.

\section{Buda}

Sente ao longe o tímido, estrangeiro peregrino: ele destila ouro,

como se, por culpa, o mundo inteiro ali juntasse os seus tesouros.

Já mais perto, mais perplexidade: vê que não foi feito dos talheres nem mesmo dos brincos das mulheres; no cílio é que reside a majestade.

Ninguém saberia sequer supor, com que coisas se fundiu, que agora cresce neste cálice de flor

tal imagem: mais muda, amarela que uma estátua de ouro, e que por fora toca o espaço, feito fosse dela. 


\section{Das Karussell}

Jardin du Luxembourg

Mit einem Dach und seinem Schatten dreht sich eine kleine Weile der Bestand von bunten Pferden, alle aus dem Land, das lange zögert, eh es untergeht.

Zwar manche sind an Wagen angespannt, doch alle haben Mut in ihren Mienen; ein böser roter Löwe geht mit ihnen und dann und wann ein weißer Elefant.

Sogar ein Hirsch ist da ganz, wie im Wald, nur daß er einen Sattel trägt und drüber ein kleines blaues Mädchen aufgeschnallt.

Und auf dem Löwen reitet weiß ein Junge und hält sich mit der kleinen heißen Hand, dieweil der Löwe Zähne zeigt und Zunge.

Und dann und wann ein weißer Elefant.

Und auf den Pferden kommen sie vorüber, auch Mädchen, helle, diesem Pferdesprunge fast schon entwachsen; mitten in dem Schwunge schauen sie auf, irgendwohin, herüber -

Und dann und wann ein weißer Elefant.

Und das geht hin und eilt sich, daß es endet, und kreist und dreht sich nur und hat kein Ziel. Ein Rot, ein Grün, ein Grau vorbeigesendet, ein kleines, kaum begonnenes Profil - . Und manchesmal ein Lächeln, hergewendet, ein seliges, das blendet und verschwendet an dieses atemlose blinde Spiel...

\section{O carrossel \\ Jardin du Luxembourg}

Com seu telhado a sombra gira e roda em um só breve instante com seus quantos cavalos coloridos de outro entanto que tanto se prolonga até sua poda. Cavalos que seu corso vão puxando, conquanto ainda indóceis e bravios; um leão vermelho e vil os segue a fio e um elefante branco quando em quando.

Um alce ali feroz como na mata, mas sobre o lombo a sela, ela e os ares de menininha azul que ali se engata.

E sobre o leão com suas mãozinhas quentes galopa firme um menininho em branco enquanto o leão lhe mostra língua e dentes.

E um elefante branco quando em quando.

E sobre os cavalinhos sempre aos pares meninas já grandinhas, mas contentes; e em meio aos seus pinotes, de repente, olhares vãos, por todos os lugares -

E um elefante branco quando em quando.

E passa, aperta o passo e então revolta, e rodopia ao léu do seu rodado. Um rubro um verde um cinza a cada volta um risco um vulto esboço a ser traçado Um riso volta e meia gira e volta, sorri assoma e some, viravolta e segue a cabra-cega do passado... 


\section{Irre im Garten}

Dijon

Noch schließt die aufgegebene Kartause sich um den Hof, als würde etwas heil. Auch die sie jetzt bewohnen, haben Pause und nehmen nicht am Leben draußen teil.

Was irgend kommen konnte, das verlief. Nun gehn sie gerne mit bekannten Wegen, und trennen sich und kommen sich entgegen, als ob sie kreisten, willig, primitiv.

Zwar manche pflegen dort die Frühlingsbeete, demütig, dürftig, hingekniet;

aber sie haben, wenn es keiner sieht, eine verheimlichte, verdrehte

Gebärde für das zarte frühe Gras, ein prüfendes, verschüchtertes Liebkosen: denn das ist freundlich, und das Rot der Rosen wird vielleicht drohend sein und Übermaß

und wird vielleicht schon wieder übersteigen, was ihre Seele wiederkennt und weiß. Dies aber läßt sich noch verschweigen: wie gut das Gras ist und wie leis.

\section{Loucos no jardim \\ Dijon}

O mosteiro de outrora ainda acolhe o pátio, como se algo ali salvasse.

É que ali quem agora se recolhe vive, como se o mundo abandonasse.

Dentro é o que fora - fora é o que revolta. Mas vai e vem e sabe seus caminhos, passa por outro e segue sozinho e volta ao que o devora a cada volta.

Há os que, pobres, humildes e ajoelhados, cuidam das flores sem desdém; e quando ninguém olha, eles têm um jeito oblíquo e rebuçado

de dar à grama tenra que engraça um carinho mais tímido e zeloso: pois isso sim é que é afetuoso, não o rubro das rosas, que ameaça

e excede o que eles pensam aguentar, e vai além do que eles sentem na alma. Quanto a isso, basta calar: como a grama é gentil e calma. 


\section{Die Irren}

Und sie schweigen, weil die Scheidewände weggenommen sind aus ihrem Sinn, und die Stunden, da man sie verstände, heben an und gehen hin.

Nächtens oft, wenn sie ans Fenster treten: plötzlich ist es alles gut.

Ihre Hände liegen im Konkreten, und das Herz ist hoch und könnte beten, und die Augen schauen ausgeruht

auf den unverhofften, oftentstellten Garten im beruhigten Geviert, der im Widerschein der fremden Welten weiterwächst und niemals sich verliert.

\section{Os loucos}

E eles calam, já que a divisória dos sentidos já não mais vigora, e as horas, tanto quanto ilusórias, levantam-se e vão se embora.

À noite em geral, quando à janela: de repente, tudo bem.

A mão no concreto a que se atrelam, alto o coração, como quem vela, e os olhos olhando o que retém

do jardim perdido ali no meio, recanto improvável e sossegado, que nos reflexos do mundo alheio vai crescendo além do seu quadrado. 


\section{Schlaflied}

Einmal wenn ich dich verlier, wirst du schlafen können, ohne dass ich wie eine Lindenkrone mich verflüstre über dir?

Ohne dass ich hier wache und Worte, beinah wie Augenlider, auf deine Brüste, auf deine Glieder niederlege, auf deinen Mund.

Ohne dass ich dich verschlie $\beta$ und dich allein mit Deinem lasse wie einen Garten mit einer Masse von Melissen und Stern-Anis.

\section{Canção de ninar}

Quando um dia eu te perder você vai dormir sem que eu, sumo dos sussurros meus, te coroe a dormecer?

Sem que eu esteja aqui e vele e grave versos, quase cílios, sobre teus seios, meu idílio, sobre a boca, sobre a pele.

Sem que eu te ponha de lado te prenda a sós com o que é teu como um jardim, um camafeu de melissa e anis-estrelado. 


\section{Mohameds Berufung}

Da aber als in sein Versteck der Hohe, sofort Erkennbare: der Engel, trat, aufrecht, der lautere und lichterlohe: da tat er allen Anspruch ab und bat

bleiben zu dürfen der von seinen Reisen innen verwirrte Kaufmann, der er war; er hatte nie gelesen - und nun gar ein solches Wort, zu viel für einen Weisen.

Der Engel aber, herrisch, wies und wies ihm, was geschrieben stand auf seinem Blatte, und gab nicht nach und wollte wieder: Lies.

Da las er: so, daß sich der Engel bog. Und war schon einer, der gelesen hatte und konnte und gehorchte und vollzog.

\section{Vocação de Maomé}

Mas quando em seu esconderijo o Altíssimo o Inconfundível: o anjo invadiu altivo e reluzente, em tom puríssimo: sem mais aspiração, ele pediu

para poder seguir seu astrolábio, confuso mercador que sempre fora; ele não tinha lido nada - e agora ver tal palavra: nem se fosse sábio.

Mas o Anjo, imperioso, por mercê mostrou-lhe em sua folha o redigido e sem descanso respondeu-lhe: Lê.

Ele leu: logo o anjo se curvou.

Agora ele era alguém que tinha lido, e foi capaz, cedeu, executou. 


\section{Buddha in der Glorie}

Mitte aller Mitten, Kern der Kerne, Mandel, die sich einschließt und versüßt, dieses Alles bis an alle Sterne ist dein Fruchtfleisch: Sei gegrüßt.

Sieh, du fühlst, wie nichts mehr an dir hängt; im Unendlichen ist deine Schale, und dort steht der starke Saft und drängt. Und von außen hilft ihm ein Gestrahle,

denn ganz oben werden deine Sonnen voll und glühend umgedreht. Doch in dir ist schon begonnen, was die Sonnen übersteht.

\section{Buda glorificado}

Centro dos centros, cerne do cerne, amêndoa que se encerra e adoça tudo, tudo, além de tudo que discerne, é tua polpa: eu te saúdo.

Veja: nada mais a ti se prende; no infinito a tua casca cia, lá o intenso sumo pulsa e estende. E um fulgor externo o auxilia,

pois teus sóis sem nem um sobressalto ardem sobre o arrebol.

Algo em ti já fez seu salto e alto dura mais que um sol. 


\section{Referências bibliográficas:}

RILKE, R. M. (2001) Die Gedichte. Frankfurt: Insel Verlag,.

(1997) Neue Gedichte/New Poems - Rainer Maria Rilke, tradução de Stephen Cohn. Manchester: Carcanet.

(1996) Werke. Kommentierte Ausgabe in vier Bänden mit einem Supplementband, vol.1 Frankfurt: Insel Verlag.

(1994) "Nouve Poesie", tradução de Giacomo Cacciapaglia. In: Poesie. Torino: Einaudi-Gallimard.

(1989) "Cartas a um jovem poeta", tradução de Paulo Rónai. In: Cartas a um jovem poeta; A canção de amor e morte do porta-estandarte Cristóvão Rilke - Rainer Maria Rilke. São Paulo: Globo. 